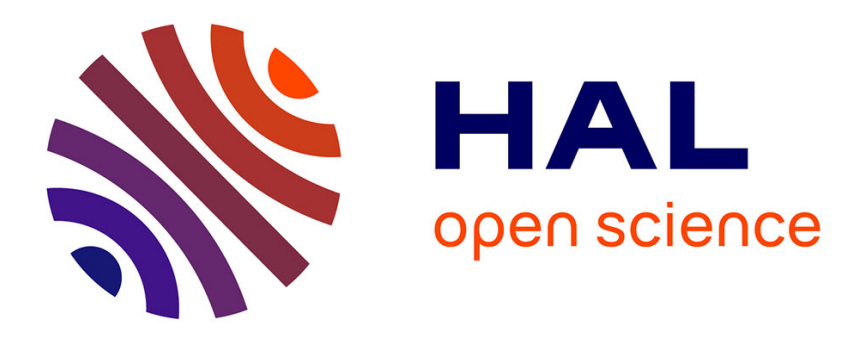

\title{
Third language acquisition: why it is interesting to generative linguists \\ Yan-Kit Ingrid Leung
}

\section{To cite this version:}

Yan-Kit Ingrid Leung. Third language acquisition: why it is interesting to generative linguists. Second Language Research, 2007, 23 (1), pp.95-114. 10.1177/0267658307071604 . hal-00570723

\section{HAL Id: hal-00570723 \\ https://hal.science/hal-00570723}

Submitted on 1 Mar 2011

HAL is a multi-disciplinary open access archive for the deposit and dissemination of scientific research documents, whether they are published or not. The documents may come from teaching and research institutions in France or abroad, or from public or private research centers.
L'archive ouverte pluridisciplinaire HAL, est destinée au dépôt et à la diffusion de documents scientifiques de niveau recherche, publiés ou non, émanant des établissements d'enseignement et de recherche français ou étrangers, des laboratoires publics ou privés. 


\section{Review article Third language acquisition: why it is interesting to generative linguists}

Yan-kit Ingrid Leung University of Essex

The present article reviews three collections of papers edited by Cenoz and colleagues on the topic of third language (L3) acquisition from perspectives including psycholinguistics, sociolinguistics and education. Our focus is on psycholinguistics, in particular, lexical acquisition studies, and with particular reference to two central notions in the study of L3, namely, language-selectiveness and cross-linguistic influence. The article also discusses expansion of the study of L3 acquisition into the Universal Grammar/Second Language Acquisition (UG/SLA) paradigm, and closes by looking at future directions for the L3 field.

Cenoz, J. and Jessner, U., editors, 2000: English in Europe: the acquisition of a third language. Multilingual Matters. In the series Bilingual education and bilingualism, edited by N.H. Hornberger and C. Baker, volume 13. xii + 271 pp. US\$39.95/GBP21.95 (paperback). ISBN 1853594792.

Cenoz, J., Hufeisen, B. and Jessner, U., editors, 2001: Cross-linguistic influence in third language acquisition: psycholinguistic perspectives. Multilingual Matters. In the series Bilingual Education and Bilingualism, edited by N.H. Hornberger and C. Baker, volume 31 . v + 197 pp. US\$54.95/GBP33.95 (hardback). ISBN 1853595497.

Cenoz, J., Hufeisen, B. and Jessner, U., editors, 2003: The multilingual lexicon. Kluwer. $\mathrm{x}+208$ pp. US $\$ 159.95 / \mathrm{GBP} 94.50$ (hardback). ISBN 1402015437.

\section{Introduction}

Third language (L3) acquisition was once subsumed under the field of second language acquisition (SLA) in which a 'second' language meant

Address for correspondence: Yan-kit Ingrid Leung, Department of Language and Linguistics, University of Essex, Wivenhoe Park, Colchester, Essex CO4 3SQ, UK; email: ileung@essex.ac.uk 
any non-native language acquired beyond the first. In recent years, a number of researchers have started to look seriously at the phenomenon of L3/multilingualism as a separate domain of inquiry. Both in Europe and in North America, the study of L3 is rapidly expanding, especially within applied linguistics, applied psycholinguistics, bilingualism and language education. This encouraging trend was marked by the biennial International Conference on Third Language Acquisition and Multilingualism, held for the fourth time in September 2005 in Fribourg and Biel, Switzerland. Notably, linguists who adopt Universal Grammar (UG) theory to address language acquisition have shown growing interest in L3 in the past three years. The volumes reviewed here reflect research conducted in this exciting young field.

Section II of this article summarizes and evaluates the contents of the three books under review. Section III pinpoints two important themes, examining more closely and critically how L3 researchers working within different theoretical frameworks have approached the issues of language selectiveness and cross-linguistic influence. ${ }^{1}$ I show how findings both included in the books under review as well as those reported elsewhere shed light on these issues. Section IV surveys the very new area of L3 syntax, as an example of what may be gained by looking at L3 from a UG perspective. Section V offers an outlook on the future, presenting topics L3 researchers might pursue. I also speculate about what L3 might gain from its independence from, and interdependence with, its mother field of SLA.

\section{A review of the three books}

\section{Cenoz and Jessner, 2000}

This is a collection of studies under the broad theme of the status of English as an L3 in Europe. The studies fall into four groups: sociolinguistics (Part I), general issues (Part II), psycholinguistics (Part III) and education (Part IV). In Part I, Charlotte Hoffmann (Chapter 1)

\footnotetext{
${ }^{1}$ It is controversial as to whether bilinguals access/activate either or both of the languages during lexical processing. Psycholinguists have termed the debate 'language selective vs. language non-selective'. On another note, 'cross-linguistic influence' and 'transfer' mean the same thing in this article, and I use the two terms interchangeably (but, for a fine-grained distinction of all related terms involved, see Sharwood Smith and Kellerman, 1986: 1).
} 
and Allan R. James (Chapter 2) look at the issue of language contact in Europe, in particular, the growing dominance of English in relation to multilingualism. Part II deals with general issues pertinent to L3/multilingualism research. It starts off with Jasone Cenoz's state-of-the-art paper (Chapter 3) in which she elucidates differences between second language acquisition and multilingual language acquisition and the link of child bilingualism to L3 acquisition. Jim Cummins's article (Chapter 4) defends his distinction between academic and conversational proficiency in bilingual (and trilingual) education. Philip Herdina and Ulrike Jessner (Chapter 5) discuss the differences between bilingualism and trilingualism and argue for a dynamic model of multilingualism to capture the complex multilingual psycholinguistic system involved.

The three psycholinguistic studies in Part III are more experimental/ empirical in nature. Istvan Kecskés and Tunde Papp (Chapter 6) investigate conceptual fluency adopting one version of the multicompetence view, that is, a common underlying conceptual base. They find that metaphorical density (i.e. proportion of metaphorical expressions produced) in L $n$ is not connected to that in L1. Ute Schönpflug (Chapter 7) reports on a written word fragment completion study on L1 Polish-L2 English-L3 German; the results demonstrate differential reaction times and error rates for German word completions and for English word completions, pointing to the possibility that the two mental lexicons are represented separately and accessed differentially online. Christine Bouvy (Chapter 8) looks at cross-linguistic transfer from L2 to L3, in the case of L1 French-L2 Dutch or German-L3 English and concludes that transfer as a means of compensation is a feature of performance.

Part IV (Chapters 9 to 13) deals with European education systems and pedagogical issues. The chapters relate to the contexts of Catalonia, the Basque Country, Finland, Friesland and Romania. The final Chapter 14 is an overview and conclusion by the editors summarizing the studies and surveying the future of multilingualism research.

I find the diverse chapters in this volume rather amazing in their presentation of a wide variety of multilingual situations and spoken languages. A few linguistically- and psycholinguistically-relevant issues brought up in the book (such as cross-linguistic influence and online processing in relation to L3 and the multilingual mind), although not rigorously investigated, provide some food for thought for 
researchers. Those who would like to know more about the sociolinguistics/socio-pragmatics and educational aspects of multilingualism within the context of continental Europe shall find this book a useful reference.

\section{Cenoz, Hufeisen and Jessner, 2001}

This second volume is more focused. It is a collection of more experimental psycholinguistic studies addressing issues mainly of L3 vocabulary development and tri-/multi-lingual lexical representation and processing. Chapter 1 'The effect of linguistic distance, L2 status and age on cross-linguistic influence in L3 acquisition' by Jasone Cenoz presents some evidence that linguistic distance rather than the L2 factor is a stronger predictor for cross-linguistic influence in L3. Chapter 2 'Roles of L1 and L2 in L3 production and acquisition' by Björn Hammarberg reports a case study of an L1 English-L2 German (also Italian and French)-L3 Swedish participant and addresses the issue of the L2 status. It is found that the L1 serves as the predominant external instrumental language fulfilling the pragmatic function in conversation in the initial phases of L3 development, while the principal L2 serves as the predominant external supplier language in L3 lexical construction over the course of acquisition. Some L1-L2 interaction in the production process is also observed. Chapter 3 'Interlanguage transfer and competing linguistic systems in the multilingual mind' by Gessica De Angelis and Larry Selinker, studies two multilinguals in England with reference to two types of interlanguage transfer: morphological and lexical. The authors also make inferences about how the (perceived) similarity of languages in terms of form influences lexical processing. In Chapter 4, 'Lexical transfer in L3 production', Håkan Ringbom posits that meaning-based errors are always L1-derived, while form-based errors could come from either L1 or L2 and are constrained by psychotypology. ${ }^{2}$ Chapter 5 'Activation or inhibition? The interaction of L1, L2 and L3 on the language mode continuum' by Jean-Marc Dewaele reports a study involving 25 L1 Dutch-L2

\footnotetext{
2'Psychotypology' denotes learners' perceived closeness of the source and target languages involved in a case of non-primary language acquisition (see Kellerman, 1979; 1983).
} 
French-L3 English trilingual university students; his findings suggest that the degree of formality of the situation, the status of the interlanguage (L2 or L3), as well as frequency of use of target language outside of the classroom affect the choice of language mode (i.e. which language to use dominantly and how much of the other language(s) to keep active) and performance.

Chapter 6 'Lexical retrieval in a third language: Evidence from errors and tip-of-the-tongue states' by Peter Ecke is an experimental study employing a written translation task on L1 Spanish-L2 English (high intermediate)-L3 German participants. The major finding points to strong L2 influence in translation errors but suppressed L1 and L2 systems in the reflection of L3 tip-of-the-tongue states. Chapter 7 'Plurilingual lexical organization: Evidence from lexical processing in L1-L2-L3-L4 translation' by Anna Herwig proposes a unified network model of the multilingual lexicon from a neurolinguistic perspective. Chapter 8 'Learners of German as an L3 and their production of German prepositional verbs' by Martha Gibson, Britta Hufeisen and Gary Libben reports an L3 German study using a gap-filling written task. The general trend of accuracy results reveals that neither the L2 factor nor linguistic typology plays a role in task performance; this is at odds with what most other L3 studies have found. Chapter 9 'Too close for comfort? Sociolinguistic transfer from Japanese into Korean as an $\mathrm{L} \geqslant 3$ ' by Robert J. Fouser addresses the issue of L3 communicative competence by examining the performance of two native speakers of Australian English who are L3/Ln Korean learners with advanced but non-native Japanese background on various elicitation instruments; results suggest a heavy influence from Japanese on $\mathrm{L} 3 / \mathrm{L} n$ Korean. The final chapter, Chapter 10 'New uses for old language: Cross-linguistic and cross-gestural influence in the narratives of non-native speakers' by Eric Kellerman is not about L3 per se. However, it introduces gesture as a future research direction for the investigation of non-native language acquisition/communicative competence, and suggests how it can be used to examine cross-linguistic influence.

Given the volume's central focus on transfer/cross-linguistic influence, I agree with previous reviewers (Sanz, 2003; Odlin, 2004) on its importance for future L3 research. It is indeed difficult to pin down one single determinant of cross-linguistic influence in L3. We are still a 
long way from a definitive statement about how prior linguistic knowledge plays out in L3 acquisition, and there is still much for L3 researchers to explore.

\section{Cenoz, Hufeisen and Jessner, 2003}

The articles collected in this third volume are the most theoretical and sophisticated. In lieu of descriptive data, quite a few proposals are put forward. The subject matter is narrowed down to the mental lexicon, covering such 'core' topics as multilingual lexical processing and the neurolinguistics of multilingualism. Both production and experimental studies are included, sometimes providing rigorous data. Chapter 1 'Why investigate the multilingual lexicon', by the editors, is a general introduction. Chapter 2 to 8 centre around the notion of transfer. In Chapter 2 'Lexical processing in bilinguals and multilinguals', Ton Dijkstra attempts to extend his bilingual visual word recognition model (Bilingual Interactive Activation Model) to the multilingual mind and contends that there is a single integrated mental lexicon in which languages are non-selective. Dijkstra views multilingual and bilingual language processing as essentially similar. Chapter 3 'The transferappropriate-processing approach and the trilingual's organization of the lexicon' by Ute Schönpflug looks at factors in the speed and accuracy of word fragment completions in L2 German and L3 English. She finds that the higher the active and/or passive competence in the non-native language, the longer word fragment completion takes, due to more potential (intra-language) competitors in the mental lexicon. Chapter 4 'The nature of cross-linguistic interaction in the multilingual system' by Ulrike Jessner proposes a dynamic model of multilingualism that integrates transfer, interference, code-switching and borrowing. In Chapter 5 'Activation of lemmas in the multilingual mental lexicon and transfer in third language learning', Longxing Wei assumes a single mental lexicon and provides empirical evidence for interlanguage transfer at the lemma level. Chapter 6 'Parasitism as a default mechanism in L3 vocabulary acquisition' by Christopher J. Hall and Peter Ecke presents a powerful parasitic model of vocabulary learning, in which new target words are built into the system via connections to existing representations. L3 is thus 'parasitic' on its hosts, namely L1 and L2. The parasitic 
model predicts that there will be strong cognate effects in the multilingual mental lexicon. One is eager to see how the model could be augmented to accommodate cases involving languages with distant typology where the degree of similarity of lexical items is smaller or even non-existent. Chapter 7 'Investigating the role of prior foreign language knowledge: Translating from an unknown to a known foreign language' by Martha Gibson and Britta Hufeisen show that learners who have learned more than one foreign language have enhanced metalinguistic skills which improve their translation performance. Chapter 8 'The role of typology in the organization of the multilingual lexicon' by Jasone Cenoz reports a qualitative study on child L1 Spanish-L2 Basque-L3 English that sheds light on the question of language typology in transfer on the level of production: L1 Spanish plays a significant role in (lexical) transfer lapses owing to linguistic typology, while L2 Basque is the dominant source of interactional strategies because Basque is used in classroom interaction. In other words, Cenoz's findings point to both L1 and L2 being a possible default in L3 production.

The next two chapters - Chapter 9 by Johannes Müller-Lancé and Chapter 10 by Carol Spöttl and Michael McCarthy - are on multilingual learning issues. Chapter 11 Rita Franceschini, Daniela Zappatore and Cordula Nitsch conclude from neurolinguistic findings that age of acquisition and fluency but not typological distance result in differential brain activation on the neurological level. Finally, David Singleton in Chapter 12 gives an overview cum critique of all the studies presented and highlights important threads linking the studies with respect to cross-lexical interaction and full integration of mental lexicons, and evaluates the various lexical processing models proposed in the book.

\section{Two themes in research on multilingual lexical processing}

Thus L3/multilingual lexical processing research has identified a number of pertinent issues around the nature of the mental lexicon and the interaction of the different languages. I discuss two prominent interrelated issues in this section:

1) single vs. multiple lexicons and language selective vs. languagenon-selective lexical access; 
2) typology vs. the 'second language (L2) factor' 3 as determinants of source of cross-linguistic influence.

My reading of the literature is that theoretical psycholinguistic model-building papers and some online controlled experimental psycholinguistic studies tend to focus on (1), usually as carry-overs from bilingualism research testing monolingual models in the bi-/tri-lingual mind, with less interest in learning-related matters. On the other hand, descriptive applied psycholinguistic production or code-switching studies concerned with language learning and transfer tend to look at (2). (Unsurprisingly, this mirrors the broad field of SLA, where generative linguistics contrasts with applied linguistics.) There are of course reverse and even overlap cases. Combining insights from (1) and (2) would clearly help us better understand the nature and functioning of the multilingual mind on the lexical level.

\section{Single vs. multiple lexicons and selective vs. non-selective lexical access}

The issue of language selectiveness in L3 is an extension of bilingualism research in which empirical evidence from psycholinguistic and neurolinguistic perspectives seems to favour language-non-selective access (cf. Smith, 1997; De Groot, 2002; De Bot, 2004). ${ }^{4}$ The issue of storage in bilingualism is now less important i.e. whether there is one single integrated lexicon (e.g. Cook, 1996) or two separate lexicons (Smith, 1997: 148-51; Singleton, 2001) or two subsystems under one big system (Paradis, 2000). The majority of empirical evidence reveals that during bilingual lexical access, even if the two languages are indeed represented differently, both are activated, although perhaps to

\footnotetext{
${ }^{3}$ The 'second language (L2) factor' in L3 acquisition refers to the general tendency to transfer (representations) from L2(s) rather than L1. In online processing/performance terms, 'L2 status' is usually used to expresses the idea of general tendency to activate L2(s) rather than L1. See below for further exposition.

${ }^{4}$ Note that in this review article, I ignore controversial topics in the lexical processing literature such as what grammatical information lexical entries contain, the number of levels of lexical representation and their nature, the distinction between conceptual and semantic features (see, e.g., Jiang, 2002), etc. I am interested in the broad idea of the lexicon of each language as a whole, and I adopt the simplistic notion of a 'word' as the holistic unit of lexical representation.
} 
different degrees (see below). In the trilingualism/multilingualism/L3 lexical processing research reviewed in Section II, Dijkstra (2003) and Wei (2003) argued for a unified lexicon with language non-selectiveness (notice that Dijkstra focused on visual perception whereas Wei dealt with production). Hall and Ecke's (2003) article also implied the same stance but the authors identified different sources of transfer on different levels of representation (compare (2) below). Spöttl and McCarthy (2003) were doubtful of the interpretation of (functionally) independent lexicons. ${ }^{5}$ In contrast, Herwig (2003) allowed for language selectiveness in the big network system and Schönpflug (2000) saw the possibility that lexicons of different languages in a multilingual mind are presented separately and accessed differentially online.

In addition to these reports, a well-controlled L3 visual perceptual experimental study by Lemhöfer et al. (2004) independently lends support to language non-selectiveness. Lemhöfer et al. look at facilitating cognate effects in trilingual processing. In one experiment, they investigated 28 Dutch-English-German trilinguals using a simple German lexical decision task with three types of test items: Dutch-German-English cognates ('triple' cognates), e.g. Hotel, Dutch-German cognates ('double' cognates), e.g. macht (English has a different word), as well as German control words ('monolingual' words without English or Dutch cognates). Participants had to decide whether each German test item was a real word. Multilingual participants responded to German test items faster in the case of Dutch-German cognates, than did German controls (no cognates). This replicated the usual cognate effect, that L1 affects target language word recognition. Responses were even faster when the test item was a 'triple' Dutch-German-English cognate than a 'double' DutchGerman cognate. This demonstrates that English (L2) helps to speed up German (L3) word recognition. These findings point to non-selective lexical access in visual word recognition. That is, all languages that have been previously acquired by a multilingual are activated at the same time during lexical processing. Therefore, it is not the case that only L1 is activated or that L1 has a privileged role to play in L3 processing. The results attest to simultaneous activation and parallel

${ }^{5}$ I am not sure whether this also holds for representation in their view. 
processing as well as interaction amongst all the three languages in a trilingual mind.

Therefore, quite some findings in the bilingualism and L3/trilingualism literature suggest that all languages within a multilingual mind are activated during lexical processing. But are all languages activated to the same degree? Will one language exert a stronger influence than the others? If so, which one? The answer to the last question hinges on one or more factors. Cross-linguistic lexical access and the source and strength of interference may be constrained by variables such as L1 dominance (since the L1 is usually more utilized and has a stronger network), language proficiency (e.g. Goral, 2001), as well as recency of activation. There is also the so-called 'second language (L2) factor'/L2 status (see Hammarberg, 2001 reviewed above and footnote 3), which seems to suggest that all non-native languages are somehow 'grouped' together in the mental space as opposed to the L1, so L2 is likely be accessed faster than L3 and will likely pose a stronger influence than L1. This is very often contrasted with another important factor linguistic typology - by which either L1 or L2 could transfer, depending on which language is typologically closer to the target language. In what follows, I discuss these two factors, frequently debated in the field of L3.

\section{Typology vs. the 'second language (L2) factor' in cross-linguistic influence or lexical transfer}

Most L3 studies with a direct focus on transfer are descriptive. Contrary to what theoretical researchers claim - (see (1) above) - the implicit assumption is that different languages form separate systems in a multilingual mind, or even if languages form a holistic network then language activation is somehow selective. ${ }^{6}$

Earlier studies on L3 lexical transfer were scant. Research such as Ringbom (1986) and Singleton (1987) did not set out to explicitly test L1 vs. L2 or typology vs. L2 status. The general conclusion of these studies was that, while all the previously acquired languages potentially 
affect the development of the L3 system, linguistic typology and psychotypology play a crucial role in determining the 'privileged' source of transfer. Studies that examine the issue more systematically have emerged recently, such as those in the volumes under review. These are mostly descriptive studies of cross-lexical representation, code-mixing and transfer, which employ offline methodologies or production data. Often data do not bear on predictions derived from any theory (although exceptions are Wei, 2003; and Hall and Ecke, 2003). The studies discussed above most pertinent to the theme of typology and transfer are Wei (2003) (which looked at transfer at different representational levels but did not distinguish sources) and Hall and Ecke (2003) (which reported different sources of transfer effects on different representation levels). Cenoz (2001; 2003) also found different transfer sources for different functions, where typology seemed to be crucial for lexical transfer, but transfer of interaction strategies might reflect similar contexts of source and target language use rather than typology. Ringbom (2001) contended that form transfer is typology-based while semantic transfer is L1-based. De Angelis and Selinker (2001) inferred the role of typology in L3 production. Both Hammarberg (2001) and Ecke (2001) concluded that L2 status was the dominant factor, while Gibson et al.'s (2001) results indicated neither typology nor L2 status constrained transfer behaviour. In short, results are mixed.

Note that these L3 studies are primarily concerned with typologically related languages (with the exception of Fouser, 2001; Wei, 2003). The methodology they adopt and the language combinations involved do not always unambiguously test the distinction between typology and the L2 factor. However, two recent studies by Singleton and O'Laoire $(2004,2005)$ have successfully achieved this. Singleton and O'Laoire (2004) looked at L1 English-L2 Irish (very advanced)-L3 French using two elicitation instruments. They found that L1 English, which is considered typologically closer to French in lexical terms than Irish is, acts as the dominant source of lexical borrowing. They interpreted this result as strong support for (psycho)typology and against the L2 factor. However, Singleton and O'Laoire acknowledged that, unlike English, the participants' L2 Irish, though very advanced, was only a non-native language; thus, L1 English may simply have exerted more influence than L2 Irish. In the 2005 study, therefore, Singleton and O'Laoire 
looked at bilingual L1 Irish-English participants. They successfully replicated the 2004 results: English but not Irish showed the privileged status in cross-lexical transfer. This is strong testimony to the role of (psycho-) typology in the lexical domain.

Intriguing questions might pop up about future research prospects: what will happen if all the three languages concerned are typologically unrelated? Would the dominant source of transfer be L1 or L2, or random? Would the findings on typology hold equally for other modules, e.g. syntax? What is meant by (psycho)typology for syntactic properties? At this moment, we do not know the answers to these questions. But we do see hope in the flourishing area of multilingual lexical processing. We also see some twilight from the spread of interest in L3 to generative linguistics.

\section{Current expanding field of L3 syntax}

In the field of theoretical L2 acquisition, i.e. studies adopting linguistic theory, particularly the generative tradition (see Hawkins, 2001a; White, 2003), L3 has been relatively unexplored. Most of the research in this framework has treated L3 acquisition as another case of L2, and dismissed the role of intermediary languages in $\mathrm{L} n$ development entirely. There were, however, some rare early studies that touched on the issue of L3. Zobl (1992) and Klein (1995), for instance, compared unilinguals and multilinguals in the acquisition of various grammatical properties. However, neither experiment was designed to have a uniform group of L3 learners with a similar linguistic background. In the last two or three years, a few generative non-native language acquisition studies have arisen that explicitly aimed to deal with L3, including Lozano (2003) on L2 vs. L3 Spanish null subject related properties, Flynn et al. (2004) on child vs. adult L3 acquisition of English restrictive relative clauses by Kazakh-Russian bilingual speakers, García Mayo et al. (2005) on placeholders is and he in Basque-Spanish bilingual children's L3 English, and my own work (Leung, 2005; 2006a; 2006b; to appear) on L1 CantoneseL2 English-L3 French morphosyntax and on a related issue of verbal morphology in L1 Cantonese-L2 English-L3 Spanish. White et al. (2004) also put some emphasis on the issue of L3 in their investigation of gender and number features in Spanish interlanguage grammars. 
A growing number of dissertations and conference papers have emerged since 2005 on L3 from the generative linguistic perspective. The majority analyse the source of transfer in L3. ${ }^{7}$ These recent works testify to the increasing interest of generative SLA researchers in the domain of L3. It is indeed encouraging.

One might naturally ask: why is L3 of interest to generative researchers? Are they not concerned only about sameness? Researchers working on L3 or multilingualism are a different breed: they are concerned with linguistic differences (hence cross-linguistic influence). This reaction that some universalists - even those working on second language acquisition - are only interested in sameness is in fact quite common amongst people outside generative SLA; for a comment regarding certain L2 analyses done within the UG framework, see Odlin, 2003: 461.

To answer this question, let us assume that one of the most fundamental concerns of L3 researchers is cross-linguistic influence. Transfer has been shown in generative SLA to be mutually compatible with universalist inquiries. In other words, it is possible to look at transfer while embracing UG. In fact, transfer has been seriously investigated in a few very prominent models in the UG/SLA field: in a series of articles published in the 1990s, Schwartz and Sprouse $(1994 ; 1996)$ proposed the Full Transfer Full Access model, Vainikka and Young-Scholten (1994; 1996) proposed the Minimal Trees Hypothesis, and Eubank (1993/94; 1994) proposed the Valueless Features Hypothesis, capturing the relationship between emergence/development of functional categories and the role of L1. Hawkins and colleagues (e.g. Hawkins and Chan, 1997; Franceschina, 2001; Hawkins and Liszka, 2003; Hawkins et al., 2006), with their Failed Functional Features Hypothesis (recently known as the Representational Deficit Hypothesis), have also argued for persistent L1 influence owing to critical period effects to explain certain

\footnotetext{
${ }^{7}$ Amongst others, there is Jin (2005) on L1 Mandarin Chinese-L2 English-L3 Norwegian subjects and objects; Koster (2005) on L1 Dutch-L2 English-L3 German verb positioning; Foote (2005) on semantic transfer of aspect involving multilinguals who speak one or more Romance languages; Chin (2005) on L3 Japanese and L3 Spanish aspect; Bayona (2005) on the issue of transfer in L3 Spanish middle and impersonal constructions; Youhanaee and Dawwari (2005) on the acquisition of psych verbs in L3 English by Arabic-Persian bilinguals; Na Ranong and Leung (2005) on L1 ThaiL2 English-L3 Mandarin Chinese null subjects and null objects as well as Jaensch (in progress) on the acquisition of German DPs by Japanese-English bilinguals with differing L2 and L3 proficiency levels.
} 
fossilization problems in adult L2 grammars. All these were attempts to incorporate the element of transfer in UG/SLA research, although of course the concept itself was used and interpreted differently than in some applied linguistics approaches. Transfer in the UG/SLA tradition was meant to reflect the subtle influence of abstract L1 properties in L2 syntactic representations, despite surface facts that might not reveal obvious transfer patterns (compare White, 1992, who argued 15 years ago that parameter resetting is not simply a new name for old contrastive analysis problems; and Lardiere, to appear, who has refined the notion of L1 influence from parameter resetting to feature re-assembly).

Whether transfer is framed as the importation of subtle L1 properties, failure of parameter resetting, representational deficit or featural mapping problems, it is a misconception that generative SLA researchers are only concerned with sameness. There are generative SLA researchers who are interested in both theory building and learning-related issues such as age effects and prior linguistic influence, who would like to investigate both universal constraints as well as parameterized properties. Even hard-core SLA generativists focus on both sameness and differences in the domain of L2 (e.g. Snape, 2006; see also Hawkins, 2001b) and in the domain of L3 (Lozano, 2003). Of course, there are SLA researchers who adopt generative linguistic theory to particularly target differences, such as Flynn et al. (2004) and Leung (2005; 2006a; 2006b; to appear) discussed above.

Notoriously, Chomsky is only interested in the pure cases of monolingualism (Cook and Newson, 2007). Therefore, we need to ask the question from a different angle: to generativists who really are only interested in sameness, what can L3 offer? This is a very difficult question. The answer depends on whether one believes that the link between (generative) linguistic theory and SLA is a 'two-way street' (see Huebner, 1991; Rutherford, 1993), a heated issue which seems no longer to be asked. But it needs to be asked, in order to evaluate what multilingualism can offer generative linguists. If one accepts that SLA could contribute to linguistic theory, then obviously L3/multilingualism could contribute even one step further. Although the two notions are not necessarily related, in my opinion the study of multilingualism offers test cases of less studied natural languages for generative linguists to explore. It helps us to extend the range of languages studied and to 
explore further the nature of the language faculty: instead of testing UG in predominantly L2 English data, multilingualism can test the limits of UG much in the same vein as Genesee (2001) has argued for the case of bi-/multi-lingual L1 acquisition: in L3/multilingual non-primary acquisition, if a learner continues to learn foreign languages an $n$th time, we want to know if UG will still be functioning in a similar way as it was for L1 or L2 acquisition. In my opinion, L3 data provides an exciting pathway to further theory building.

\section{Prospects and future directions}

More than a decade ago, Rutherford (1993: 11) speculated that a shift was underway in SLA research from syntax (alone) to the lexicon and possibly to the interaction of syntax and the lexicon. The exact nature of the lexicon certainly depends on the specific model one assumes. In Minimalist terms, Rutherford's prediction seemed to be actualized in featurebased L2 accounts (e.g. Hawkins and Liszka, 2003). In addition, with Ullman's (2001) proposition that L2 syntax and L2 lexicon occupy shared brain/mental space at least at the initial stages of L2 development, I think it is not unreasonable to stress the need to study both domains in L2 - or L3 - as well. To take a simplistic view of the lexicon as a list of 'words', I have demonstrated in Section III that multilingual lexical processing is an exciting area to explore, particularly concerning crosslexical interaction. In Section IV, I argued that L3 syntax is also full of potential to uncover the role of transfer on the level of syntactic representation and interlanguage grammar formation. A researcher interested in L3 and transfer would naturally be attracted to the study of cross-lexical interaction; such a researcher with a background in generative linguistics would also be fascinated by cross-linguistic influence on abstract syntactic properties. One possible trend for L3 research, as I see it, is therefore to combine the insights from both lexical processing and theoretical syntax to bear on the role of prior linguistic knowledge, that is, to look at both the lexicon and syntax of the same L3 population to see if convergence of results could be obtained with respect to the source of transfer (cf. Na Ranong, in progress). Investigating L3 on other combined levels, such as L3 syntax and L3 semantics would be another possible direction. I should also mention one other challenging aspect which I dare not touch 
on in this article: the intricate relationship between development, representation and processing in non-native language acquisition in general, about which Truscott and Sharwood Smith (2004) make an insightful suggestion.

To conclude, I think that L3 acquisition would benefit from a greater number of studies that specifically target L3, independent of L2; in this way, the demarcation between L3 and L2 will be clearer, and our awareness of the value of L3 as a separate domain will be strengthened. At the same time, multilingualism/L3 research has a lot to borrow by way of model building from its mother field of bilingualism/SLA.

\section{Acknowledgements}

I would like to thank Margaret Thomas for inviting me to write this article and for her helpful feedback and kind assistance throughout the process. I am also grateful to the anonymous Second Language Research reviewer for the very encouraging comments and useful suggestions. All errors are my own.

\section{References}

Bayona, P. 2005: Transfer in middle and impersonal constructions in Spanish as an L3. Paper presented at the 4th International Conference on Third Language Acquisition and Multilingualism, Fribourg and Biel, Switzerland.

Chin, D.H.-J. 2005: Language transfer in the acquisition of aspect in Japanese and Spanish by multilingual learners. Paper presented at JSLA 2005, Tokyo, Japan.

Cook, V. 1996: Competence and multi-competence. In Brown, G., Malmkjær, K. and Williams, J., editors, Performance and competence in second language acquisition. Cambridge University Press, 57-69.

Cook, V. and Newson, M. 2007: Chomsky's Universal Grammar. 3rd edition. Blackwell.

De Bot, K. 2004: The multilingual lexicon: modelling selection and control. International Journal of Multilingualism 1, 17-32.

De Groot, A.M.B. 2002: Lexical representation and lexical processing in the L2 user. In Cook, V., editor, Portraits of the L2 user. Multilingual Matters, 32-64.

Eubank, L. 1993/94: On the transfer of parametric values in L2 development. Language Acquisition 3, 183-208. 
1994: Optionality and the initial state in L2 development. In Hoekstra, T. and Schwartz, B.D., editors, Language acquisition studies in generative grammar. John Benjamins, 369-88.

Flynn, S., Foley, C. and Vinnitskaya, I. 2004: The cumulative-enhancement model for language acquisition: comparing adults' and children's patterns of development in first, second and third language acquisition of relative clauses. The International Journal of Multilingualism 1, $3-16$.

Foote, R. 2005: Semantic transfer in L3 acquisition: the role of typology. Paper presented at AIAL 2005/The 14th World Congress of Applied Linguistics, Madison, WI.

Franceschina, F. 2001: Morphological or syntactic deficits in near-native speakers? An assessment of some current proposals. Second Language Research 17, 213-47.

García Mayo, M.P., Lázaro Ibarrola, A. and Liceras, J.M. 2005: Placeholders in the English interlanguage of bilingual (Basque/Spanish) children. Language Learning 55, 445-89.

Genesee, F. 2001: Bilingual first language acquisition: exploring the limits of the language faculty. In McGroarty, M., editor, Annual review of applied linguistics: language and psychology, volume 21. Cambridge University Press, 153-68.

Goral, M. 2001: Lexical access and language proficiency of trilingual speakers. Unpublished PhD dissertation, City University of New York.

Hawkins, R. 2001a: Second language syntax: a generative introduction. Blackwell.

2001b: The theoretical significance of universal grammar in second language acquisition. Second Language Research 17, 345-67.

Hawkins, R. and Chan, C.Y.-H. 1997: The partial availability of universal grammar in second language acquisition: the 'failed functional features hypothesis'. Second Language Research 13, 187-226.

Hawkins, R. and Liszka, S. 2003: Locating the source of defective past tense marking in advanced L2 English speakers. In van Hout, R., Hulk, A., Kuiken, F. and Towell, R., editors, The interface between syntax and lexicon in second language acquisition. John Benjamins, 21-44.

Hawkins, R., Al-Eid, S., Almahboob, I., Athanasopoulos, P., Chaengchenkit, R., Hu, J., Rezai, M., Jaensch, C., Jeon, Y., Jiang, A., Leung, Y.-k.I., Matsunaga, K., Ortega, M., Sarko, G., Snape, N. and Velasco-Zárate, K. 2006: Accounting for English article interpretation by L2 speakers. In Foster-Cohen, S., Medved Krajnovic, M. and Mihaljevic Djigunovic, J., editors, EUROSLA Yearbook 6. John Benjamins, 7-25.

Huebner, T. 1991: Second language acquisition: litmus test for linguistic theory? In Huebner, T. and Ferguson, C.A., editors, Crosscurrents in second language acquisition and linguistics theories. John Benjamins, $3-22$. 
Jaensch, C. in progress: The acquisition of article and adjective endings in L2 and L3 German by Japanese native speakers. Unpublished $\mathrm{PhD}$ dissertation, University of Essex.

Jiang, N. 2002: Form-meaning mapping in vocabulary acquisition in a second language. Studies in Second Language Acquisition 24, 617-37.

Jin, F. 2005: The role of L1 and L2 in L3A. Paper presented at the 21SCL/21st Scandinavian Conference of Linguistics, NTNU, Trondheim, Norway.

Kellerman, E. 1979: Transfer and non-transfer: where we are now. Studies in Second Language Acquisition 2, 37-57.

1983: Now you see it, now you don't. In Gass, S. and Selinker, L., editors, Language transfer in language learning. John Benjamins, 112-34.

Klein, E. 1995: Second vs. third language acquisition: is there a difference? Language Learning 45, 419-65.

Koster, L. 2005: Verb positioning in L3 German: roles of the first and second languages. Unpublished MA dissertation, University of Essex.

Lardiere, D. to appear: Feature-assembly in second language acquisition. In Liceras, J.M., Zobl, H. and Goodluck, H., editors, The role of formal features in second language acquisition. Lawrence Erlbaum.

Lemhöfer, K., Dijkstra, A. and Michel, M. 2004: Three languages, one ECHO: Cognate effects in trilingual word recognition. Language and Cognitive Processes 19, 585-611.

Leung, Y.-k.I. 2005: L2 vs. L3 initial state: A comparative study of the acquisition of French DPs by Vietnamese monolinguals and Cantonese-English bilinguals. Bilingualism: Language and Cognition 8, 39-61.

_ 2006a: Full transfer vs. partial transfer in L2 and L3 acquisition. In Slabakova, R., Montrul, S., Prévost, P. and Slabakova, S., editors, Inquiries in linguistic development: in honor of Lydia White. John Benjamins, 157-87.

— 2006b: Verb morphology in L2A vs. L3A: the representation of regular and irregular past participles in English-Spanish and Chinese-EnglishSpanish interlanguages. In Foster-Cohen, S., Medved Krajnovic, M. and Mihaljevic Djigunovic, J., editors, EUROSLA Yearbook 6. John Benjamins, $27-56$.

— to appear: The verbal functional domain in L2A and L3A: tense and agreement in Cantonese-English-French interlanguage. In Liceras, J.M., Zobl, H. and Goodluck, H., editors, The role of formal features in second language acquisition. Lawrence Erlbaum.

Lozano, C. 2003: Universal Grammar and focus constraints: the acquisition of pronouns and word order in non-native Spanish. Unpublished $\mathrm{PhD}$ dissertation, University of Essex.

Na Ranong, S. in progress: Investigating lexical and syntactic transfer in L3 acquisition: the case of L1 Thai - L2 English - L3 Chinese. Unpublished $\mathrm{PhD}$ dissertation, University of Essex. 
Na Ranong, S. and Leung, Y.-k.I. 2005: The status of null subjects and null objects in L1 Thai-L2 English-L3 Chinese interlanguage grammars. Paper presented at the 11th International Conference on Processing Chinese and Other East Asian Languages (PCOEAL), Chinese University of Hong Kong, Hong Kong.

Odlin, T. 2003: Cross-linguistic influence. In Doughty, C. and Long, M., editors, The handbook of second language acquisition. Blackwell, 436-86. 2004: Review of Cenoz, Hufeisen and Jessner, editors, 2001. Studies in Second Language Acquisition 26, 474-75.

Paradis, M. 2000: Generalizable outcomes of bilingual aphasia research. Folia Phoniatrica et Logopaedica 52, 54-64.

Ringbom, H. 1986. Crosslinguistic influence and the foreign language process. In Kellerman, E. and Sharwood Smith, M., editors, Crosslinguistic influence in second language acquisition. Pergamon, 150-62.

Rutherford, W. 1993: Linguistics and SLA: the two-way street phenomenon. In Eckman, F., editor, Confluence: linguistics, L2 acquisition and speech pathology, John Benjamins, 3-14.

Sanz, C. 2003: Review of Cenoz, Hufeisen and Jessner, editors, 2001. The Modern Language Journal 87, 129-30.

Schwartz, B.D. and Sprouse, R. 1994: Word order and nominative case in nonnative language acquisition: a longitudinal study of (L1 Turkish) German interlanguage. In Hoekstra, T. and Schwartz, B.D., editors, Language acquisition studies in generative grammar. John Benjamins, 317-68.

— 1996: L2 cognitive states and the full transfer/full access model. Second Language Research 12, 40-72.

Sharwood Smith, M. and Kellerman, E. 1986: Crosslinguistic influence in second language acquisition: an introduction. In Kellerman, E. and Sharwood Smith, M., editors, Crosslinguistic influence in second language acquisition. Pergamon, 1-9.

Singleton, D. 1987: Mother and other tongue influence on learner French. Studies in Second Language Acquisition 9, 327-46.

2001: Cross-linguistic interactions in the multilingual lexicon. Paper presented at the 2nd International Conference on Third Language Acquisition and Trilingualism, Fryske Akademy, Leeuwarden/Ljouwert, Netherlands.

Singleton, D. and O'Laoire, M. 2004: Psychotypology and the 'L2 factor' in cross-lexical interaction: an analysis of English and Irish influence in learner French. Paper presented at EUROSLA-2004, Edinburgh.

_ 2005: Cross-lexical interaction in Irish-English bilinguals' French: further exploration of the psychotypology factor. Paper presented at EUROSLA-2005, Dubrovnik.

Smith, M. 1997: How do bilinguals access lexical information? In de Groot, A.M.B. and Kroll, J.F., editors, Tutorials in bilingualism: psycholinguistic perspectives. Lawrence Erlbaum, 145-68. 
Snape, N. 2006: The acquisition of the English determiner phrase by Japanese and Spanish learners of English. Unpublished PhD dissertation, University of Essex.

Truscott, J. and Sharwood Smith, M. 2004: Acquisition by processing: a modular perspective on language development. Bilingualism: Language and Cognition 7, 1-20.

Ullman, M. 2001: The neural basis of lexicon and grammar in first and second language acquisition: the declarative/procedural model. Bilingualism: Language and Cognition 4, 105-22.

Vainikka, A. and Young-Scholten, M. 1994: Direct access to X'-theory: evidence from Korean and Turkish adults learning German. In Hoekstra, T. and Schwartz, B.D., editors, Language acquisition studies in generative grammar. John Benjamins, 265-316.

— 1996: Gradual development of L2 phrase structure. Second Language Research 12, 7-39.

White, L. 1992: Universal Grammar: is it just a new name for old problems?. In Gass, S. and Selinker, L., editors, Language transfer in language learning, revised edition. John Benjamins, 217-32.

— 2003: Second language acquisition and Universal Grammar. Cambridge University Press.

White, L., Valenzuela, E., Kozlowska-Macgregor, M. and Leung, Y.-k.I. 2004: Gender agreement in L2 Spanish: evidence against failed features. Applied Psycholinguistics 25, 105-33.

Youhanaee, M. and Dawwari, M. 2005: The acquisition of psych verbs by Arabic-Persian bilinguals. Paper presented at the 4th International Conference on Third Language Acquisition and Multilingualism, Fribourg and Biel, Switzerland.

Zobl, H. 1992: Prior linguistic knowledge and the conservatism of the learning procedure: grammaticality judgements of unilingual and multilingual learners. In Gass, S. and Selinker, L, editors, Language transfer in language learning, revised edition. John Benjamins, 177-96. 